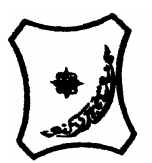

Bayero Journal of Pure and Applied Sciences, 9(2): 179 - 185

Received: June, 2016

Accepted: November, 2016

ISSN $2006-6996$

\title{
ADOPTION AND USE OF A UNIVERSITY REGISTRATION PORTAL BY UNDERGRADUATE STUDENTS OF BAYERO UNIVERSITY, KANO
}

\author{
Galadanci, B. S. ${ }^{1}$ and Abdulwahab, . $^{2}$ \\ 1. Department of Software Engineering, Bayero University, Kano, Nigeria. \\ 2. Department of Information Technology, Bayero University, Kano, Nigeria. \\ Corresponding Author's Email: bashirgaladanci@yahoo.com
}

\section{ABSTRACT}

The impact of Information Technology (IT) has continued to increase in all aspects of our lives; there has been increasing interest in research on the factors that explain user acceptance of new technology. Venkatesh combined eight of the most popular models to formulate a new model, called the Unified Theory of Acceptance and Use of Technology (UTAUT), which since then has become one of the most prominent models. This paper tries to validate a modified UTAUT model for the Bayero University, Kano. Students' registration portal which every university student has to use at the beginning of every academic session was used to test the model. Three hundred and sixty eight valid questionnaires were used to validate research model which comprises five constructs in the modified model namely: performance expectancy (PE), effort expectancy (EE), social influence (SI), facilitating conditions (FC) and anxiety (AX). In order to evaluate the internal consistency, convergence and discernments validity, confirmatory factor analysis (CFA) is run on the measurement model and the values of Average Variance Extracted (AVE), Composite Reliability ( $\rho c)$, and Cronbach's Alpha (CA) are found to be satisfactory. The data collected is analyzed using structural equation modeling techniques. Three major constructs of the model - performance expectancy (PE), effort expectancy (EE) and social influence (SI) - are found to be insignificant determinants of registration portal usage, showing that there are a number of systems that may neither fit into the UTAUT nor UTAUT2 models because of their special characteristics.

Keywords: IT, myBUK, UTAUT, University registration portal, Structural Equation Modeling

\section{INTRODUCTION}

As the impact and adoption of Information Technology has continued to increase in all aspects of our lives, there has been increasing interest in research on the factors that drive user acceptance of new technology. Prior to the year 2003, several theoretical models, with roots in different academic disciplines, appeared trying to account for these factors. Venkatesh, Morris, Davis, and Davis (2003) combined eight of the most popular models to formulate a new model, called the Unified Theory of Acceptance and Use of Technology (UTAUT), which since then has become one of the most prominent models in Information Systems. There have been several empirical validations of UTAUT with several IT systems and in diverse settings, countries and cultures (Venkatesh, Thong, \& Xu, 2012). Many of these have validated the four constructs of the model. There have been a few attempts to validate UTAUT for a number of IT systems in Nigeria (Abdulwahab \& Zulkhairi, 2012. This paper tries to validate UTAUT model using Bayero University, Kano registration portal, popularly called the "myBuk" portal, which every university student has to use at the beginning of every academic session in order to get fully enrolled and registered. The IT systems is considered as a case of a mandatory system that has to be used rather than voluntary systems for which there could be an alternative. Such as Automatic Teller Machine (ATM), for example where a user has the alternative of going into the banking hall and doing any of the ATM transactions there.

Related Work

There are several theoretical models, with roots in different academic disciplines that have appeared trying to explain the factors that determine user acceptance of new technology.

They include the Theory of Reasoned Action (TRA) Fishbein and Ajzen, (1975), drawn from social psychology, the Technology Acceptance Model (TAM), (Davis, 1989), which predicts the acceptance and usage of Information Technology and the Motivational Model (MM), (Davis et al., 1992), which uses general motivation theory to explain behavior. Others are the Theory of Planned Behavior (TPB), (Ajzen, 1991), that is an extension of TRA, the Combined TAM and TPB (C-TAM-TPB), (Taylor \& Todd, 1995), that is a hybrid of TPB and TAM, and Model of PC Utilization (MPCU), (Thompson et al., 1991), that is derived from Triandis Theory of Human Behavior. The Innovation Diffusion Theory (IDT), (Rogers, 1995), used in explaining the adoption of innovations and the Social Cognitive Theory (SCT), (Bandura, 1986), are also powerful theories that have been used to explain user acceptance and usage of technology. They are the eight models that Venkatesh et al. (2003) combined to formulate the Unified Theory of Acceptance and Use of Technology (UTAUT) that has widely been validated for several IT systems in diverse settings, countries and cultures. 
BAJOPAS Volume 9 Number 2 December, 2016

The original UTAUT model was validated with a commercial organization where IT systems are used to improve worker productivity and the general efficiency of the organization. However, with the high proliferation of IT use amongst students, there have been several studies that attempted to validate UTAUT for IT systems used in universities and other higher institutions of learning for academic purposes. Later Venkatesh et al. (2012) extended UTAUT to consumer systems coming up with UTAUT2 which incorporated three additional constructs namely hedonic motivation, price value, and habit. This made the overall scope coverage of UTAUT and UTAUT2 ever wider encompassing virtually all types of IT systems. In spite of this wide coverage, it appears that there are systems that neither fit into UTAUT nor
UTAUT2. There are systems, for example, that is used in an organizational setting but may not be perceived to be adding value to the performance of those using them. An illustration of this type of system is the "myBUK" portal, which Bayero University Kano uses to register all its students at the beginning of every academic session. In this study, an attempt is made to validate myBUK with the original UTAUT model.

\section{Conceptual Model}

The UTAUT model proposed by Venkatesh et al. (2003), that is used in this research, has four constructs namely performance expectancy, effort expectancy, social influence, facilitating conditions that determine the behavioral intent and two constructs influencing usage behavior namely behavioral intent and facilitating conditions.

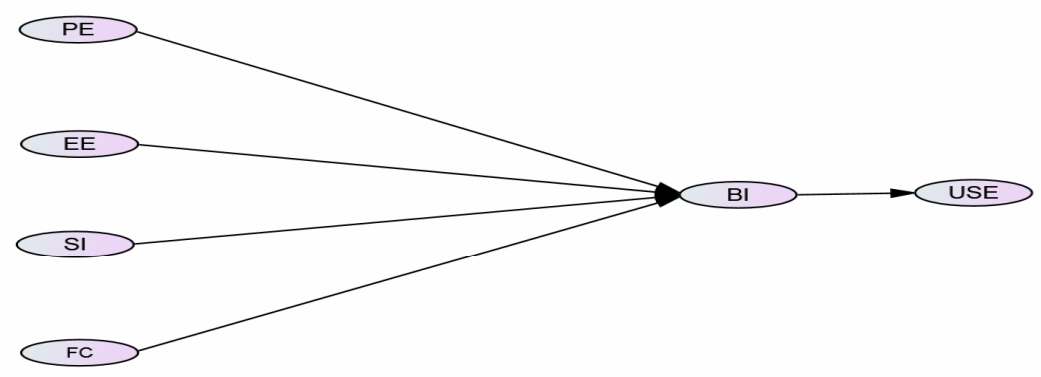

Figure 1. UTAUT Model

The definitions of the constructs are given in Table 1 below:

Table 1: Definitions of Constructs in the UTAUT Model

\begin{tabular}{|c|c|c|}
\hline $\begin{array}{l}\mathbf{S} / \mathbf{N} \\
1 .\end{array}$ & $\begin{array}{l}\text { Construct } \\
\text { Performance } \\
\text { Expectancy }\end{array}$ & $\begin{array}{l}\text { Definition } \\
\text { The degree to which an individual believes that using the system will } \\
\text { help him or her to attain gains in job performance. }\end{array}$ \\
\hline 2. & $\begin{array}{l}\text { Effort } \\
\text { Expectancy }\end{array}$ & The degree of ease associated with the use of the system. \\
\hline 3. & Social Influence & $\begin{array}{l}\text { The degree to which an individual perceives that important others } \\
\text { believe he or she should use the new system. }\end{array}$ \\
\hline 4. & $\begin{array}{l}\text { Facilitating } \\
\text { Conditions }\end{array}$ & $\begin{array}{l}\text { The degree to which an individual believes that an organizational and } \\
\text { technical infrastructure exists to support use of the system. }\end{array}$ \\
\hline 5. & Anxiety & $\begin{array}{l}\text { The degree to which an individual is apprehensive of using the } \\
\text { system }\end{array}$ \\
\hline 6. & $\begin{array}{l}\text { Behavioral } \\
\text { Intention }\end{array}$ & $\begin{array}{l}\text { The degree to which an individual will engage in a particular } \\
\text { behavior. }\end{array}$ \\
\hline
\end{tabular}

Sources Venkatesh et al. (2003) 


\section{Methodology}

The acceptance of the "myBUK" registration portal was investigated using a slightly modified model to the original UTAUT model proposed by Venkatesh et al. (2003). The model postulates that there are six constructs, namely performance expectancy (PE), effort expectancy (EE), social influence (SI), facilitating conditions (FC) and anxiety ( $A X)$, that determine the behavioral intent and two constructs, namely behavioral intent and facilitating conditions, that influence usage behavior. All the constructs used are as defined in Venkatesh et al. (2003) and as earlier given in Table 1. The study uses a close ended questionnaire as instruments for collecting data from the respondents. The questionnaire was adapted based on a 7- point Likert scale in measuring the constructs, including endogenous and exogenous variables (Davis et al., 1989; Karahanna et al. 1999; Bhattacherjee, 2001; Liao et al., 2008; Venkatesh et al., 2012). An individual chooses a scale from the ranges of seven scales starting from "strongly disagree" to "strongly agree". The interval scale was selected because it can measure the degree of the difference in the preference among the individual (Sekaran, 2006).

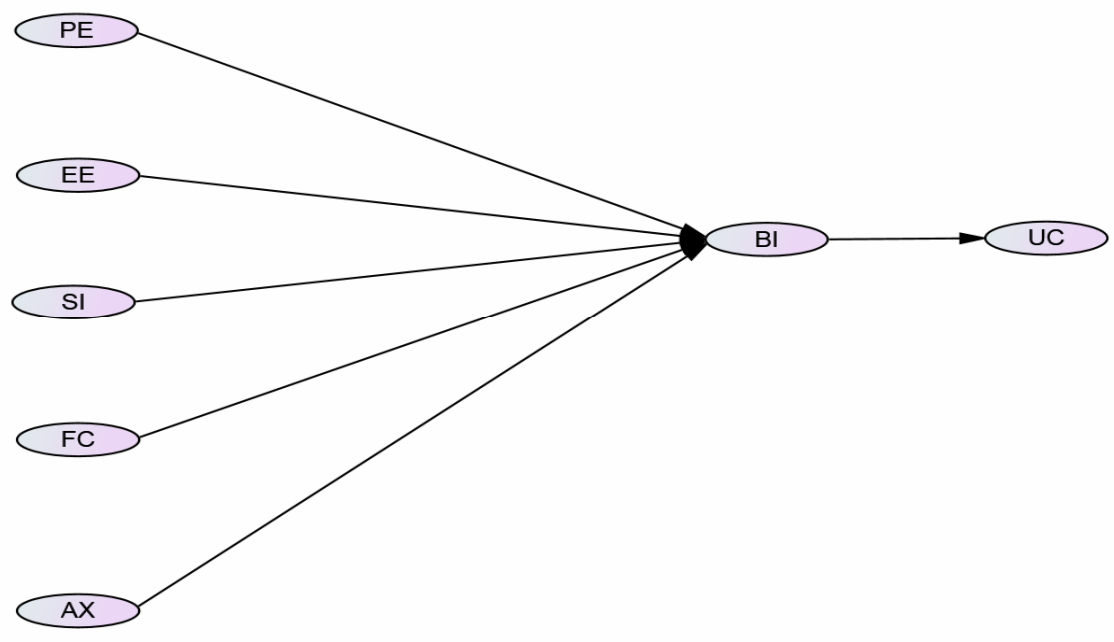

Figure 2. Research Model

\section{Data collection}

The data collection was conducted by distributing close ended questionnaires to undergraduate students of the Department of Computer Science, Bayero University, Kano, Nigeria using random sampling. Four hundred and sixty (460) questionnaires were distributed to the respondents out of which 390 were retrieved. Of this number 368 was found valid for conducting the analysis. The structural equation modeling techniques was used to evaluate the research model using AMOS 7.0 Computer software as a tool for conducting the hypothesis testing

\section{RESULTS}

Table 2, Shows the demographic characteristics of the respondents. There were a total of 368 respondents that were spread amongst the undergraduate students of the Department with 172 in Level I, 62 in Level II, 16 in Level III and 118 in Level IV. Two hundred and sixty eight of the respondents, representing $73 \%$ of the respondents were male while the remaining $100(27 \%)$ were female maintaining the gender ratio of the Department's student population. $35 \%$ of the respondents were in the $15-$ 20 years old bracket while $53 \%$ were in the $21-25$ years old bracket. The remaining $12 \%$ were above 25 years old. $41 \%$ of the respondents reported that they had been using the myBUK portal for more than 2 semesters with $17 \%$ stating that they had used it for only 2 semesters and $42 \%$ reporting that they had used it for only 1 semester. Apparently, majority of the respondents had never had any training on using the portal; 291 (79\%) reported that they had no training with $58(16 \%)$ stating that they had less than 5 hours of training and $19(5 \%)$ reporting that they had more than 5 hours of training on how to use the portal. 
BAJOPAS Volume 9 Number 2 December, 2016

Table 2. Demographic Characteristics of the Respondents

\begin{tabular}{lcc}
\hline Gender & Frequency & Percentage \\
Male & 268 & 73 \\
Female & 100 & 27 \\
Age & & \\
$15-20$ & 129 & 35 \\
$21-25$ & 194 & 53 \\
$26-30$ & 43 & 12 \\
Academic Year & 172 & 47 \\
First year & 62 & 17 \\
Second & 16 & 4 \\
Third & 118 & 32 \\
Fourth & 155 & 42 \\
Duration for my BUK Usage & 62 & 17 \\
0-1 Semester & 151 & 41 \\
2 Semesters & & \\
More than 2 semesters & & 79 \\
Duration for my BUK & 291 & 16 \\
Training & 58 & 5 \\
None & 19 & \\
0-5 hours & & \\
Greater than 5 hours & &
\end{tabular}

\section{Measurement Model}

A two-step approach was used in the study to test the hypothesized model, as given by Anderson and Gerbing (1988) and Hair et al. (2010) starting with the purification of the measurement model followed by the investigation and evaluation of the theoretical model.

\section{Reliability Analysis}

Confirmatory factor analysis (CFA) was run on the measurement model in order to evaluate the internal consistency, convergence and discernments validity.
The reliability was measured, as explained in Sekaran (2006), to indicate the extent to which the instruments are free from random error and to measure how stable they are across time and the various items in the scale. The values of Average Variance Extracted (AVE), Composite Reliability $(\rho c)$, and Cronbach's Alpha (CA) were calculated and found to be satisfactory according to Fornell and Larker (1981) and Geffen \& Straub (2005). Table 3, shows the psychometric properties of the measures.

Table 3. Shows the psychometric properties of the measures

\begin{tabular}{llll}
\hline Construct & AVE & CR $(\tilde{\boldsymbol{n}} \boldsymbol{c})$ & CA \\
Anxiety & 0.567 & 0.796 & 0.792 \\
Facilitating Conditions & 0.529 & 0.771 & 0.795 \\
Social Influence & 0.521 & 0.765 & 0.765 \\
Effort Expectancy & 0.502 & 0.751 & 0.758 \\
Performance Expectancy & 0.629 & 0.834 & 0.826 \\
Behavioral Intention & 0.530 & 0.771 & 0.769 \\
Usage & 0.624 & 0.832 & 0.829 \\
\hline
\end{tabular}

The Composite reliability (CR) values, ranging from 0.751 to 0.832 , are well above the recommended threshold of 0.70 just as the Cronbach alpha (CA) figures, ranging from 0.758 to 0.829 , are also above the reliability threshold of 0.7 (Nunally \& Bernstein, 1994). The values of average variances extracted $(\mathrm{AVE})$, used to establish discriminant validity, and are

above 0.5 for all the constructs. Furthermore, as shown in Table 4, the values of the square roots of the extracted (AVE) for all the constructs are found to exceed the inter-correlation of the construct with the other constructs in the model (Chin, 2010; Fornell \& Larcker, 1981).

Table 4.Correlations among the constructs

\begin{tabular}{llllllll}
\hline & ANX & FC & SI & EE & PE & BI & US \\
ANX & 0.753 & & & & & & \\
FC & 0.136 & 0.727 & & & & & \\
SI & 0.258 & 0379 & 0.722 & & & & \\
EE & 0.083 & 0.709 & $0 . .626$ & 0.709 & & & \\
PE & 0.087 & 0.591 & 0.478 & 0.762 & 0.793 & & \\
BI & 0.258 & 0.509 & 0.379 & 0.469 & 0.406 & 0.728 & \\
US & 0.262 & 0.318 & 0.358 & 0.341 & 0.209 & 0.318 & 0.790 \\
\hline
\end{tabular}

Diagonal elements are square roots of the average variance extracted (AVE) 
Extant studies have suggested the use of some goodness-of-fit (gof) indices (Gefen \& Straub, 2005; Chin, 2010). The CMIN/DF (i.e. ratio) of the model was 1.398. The value is clearly less than the cut-off criterion of 3 as recommended by Bagozzi and YI (1988) and in the same way the next fit indices for the measurement model are satisfactory. The adjusted goodness of fit index (AGFI) was 0.923 which exceeds the recommended value of 0.8 (Chau \& $\mathrm{HU}, 2001$ ) just as the comparative fit index (CFI) and the Tucker Lewis Index (TLI) of 0.976 and 0.970 respectively are greater than the 0.9 recommended by (Bagozzi \& YI, 1988). The root mean square error approximation (RMSEA) value of 0.033 is also lower than the recommended value of 0.08 (Browne \& Cudeck, 1993). Thus, as shown in Table 5, all the Quality-of-Fit measures were well above the recommended levels suggested by previous researches (Bagozzi \& YI, 1988; Gefen \& Straub, 2005; Chin, 2010). It can be said, therefore, that the measurement model fits with the data collected.

Table 5.Goodness of fit (gof) index for the measurement model

\begin{tabular}{lll}
\hline $\begin{array}{l}\text { Quality-of-fit } \\
\text { measure }\end{array}$ & Recommended value & Measurement model \\
X $^{2} / d f$ & $\leq 3.00$ & \\
AGFI & $\geq 0.80$ & 1.398 \\
CFI & $\geq 0.90$ & 0.923 \\
TLI & $\geq 0.90$ & 0.976 \\
RMSEA & $\leq 0.08$ & 0.970 \\
\hline
\end{tabular}

Using structural model analysis, the path coefficients were calculated in order to estimate the strengths of the relationships between the endogenous and exogenous variables, as explained in Bagozzi and $\mathrm{Yi}$ (1988). The standardized path coefficients in the hypothesized model, as in Fig. 3 shows that performance expectancy ( $\hat{a}_{\mathrm{PE}}=0.042 ; \mathrm{t}=0.117$ ), effort expectancy ( $\left.\hat{a}_{\mathrm{EE}}=0.114 ; \mathrm{t}=0.133\right)$ and social influence $\left(\hat{a}_{\mathrm{SI}}=0.153 ; \mathrm{t}=0.090\right.$ ) are all not significant determinants of behavioral intention; and, On the other hand facilitating conditions $\left(\hat{a}_{\mathrm{FC}}=0.346\right.$; $\mathrm{t}=0.097 ; \mathrm{p}<0.001)$ and anxiety $\left(\hat{\mathrm{a}}_{\mathrm{Ax}}=0.127 ; \mathrm{t}=\right.$ $0.043 ; \mathrm{p}<0.05)$ from the standardized path coefficients, are significant determinants of behavioral intention and). Furthermore, behavioral intention (âp $=0.437 ; \mathrm{t}=0.089 ; \mathrm{p}<0.001)$ is also a significant determinant of usage. The estimated model equation is shown in Equation (1).

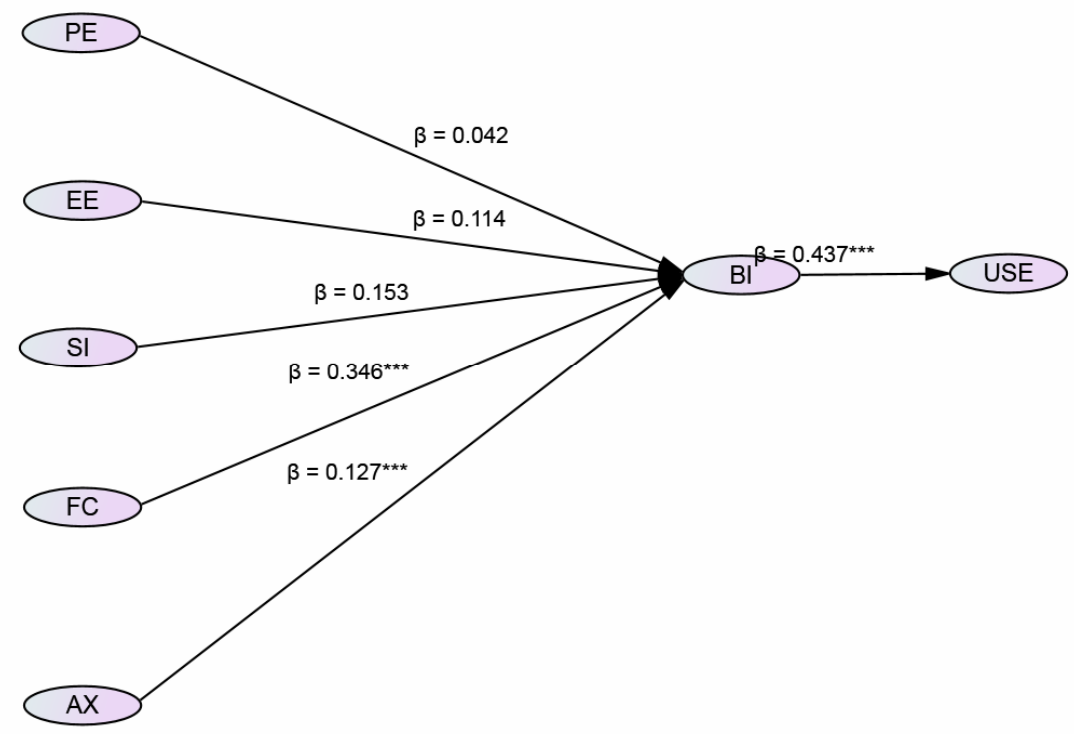

Figure 3. Estimated Research Model $\mathrm{P}<0.05 * * * \quad \mathrm{P}>0.05 \mathrm{~ns}$

USE $=\hat{a}_{\mathrm{BI}} 0.418+\hat{a}_{\mathrm{FC}} 0.346+\hat{a}_{\mathrm{AX}} 0.127 \quad \ldots \ldots . . . \quad$ Equation (1). 


\section{DISCUSSION}

The study tried to validate the Unified Theory on the Acceptance and Use of Technology (UTAUT) for the "myBUK" portal which is a registration portal that is used by all undergraduate students of Bayero University, Kano (BUK) students to annually update their records and register courses for new academic session and to make necessary payments. The model to be validated had four constructs that determine behavioral intention and two constructs that established usage. The results of hypotheses testing are shown in Table 6.

Table 6. Results of Hypotheses Testing

\begin{tabular}{lll}
\hline pothesis & & Result \\
$\mathrm{H}_{\mathrm{A} 1}$ & Performance Expectancy has a positive effect on behavioral intention & Not supported \\
$\mathrm{H}_{\mathrm{A} 2}$ & Effort Expectancy has a positive effect on behavioral intention & Not supported \\
$\mathrm{H}_{\mathrm{A} 3}$ & Social influence has a positive effect on behavioral intention & Not Supported \\
$\mathrm{H}_{\mathrm{A} 4}$ & Facilitating Condition has a positive effect on behavioral intention & Supported \\
$\mathrm{H}_{\mathrm{A} 5}$ & Anxiety has a positive effect on behavioral intention & Supported \\
$\mathrm{H}_{\mathrm{A} 6}$ & Behavioral Intention has a positive effect on usage & Supported \\
\hline
\end{tabular}

Clearly, the results are substantially different from those studies conducted using UTAUT model that was being tested. It would appear that the myBUK registration portal is quite different from other IT platform. This may be because the portal is just used to register students at the beginning of each academic session and so, the use of the portal by itself is not expected to contribute to the academic achievements of the students. Thus, it is not surprising that the respondents do not consider the portal to improve their performance. Also, majority of the students are not likely to consider the myBUK registration portal to be easy to use (effort expectancy) because most of them go to Internet cafes to carry out the registration process (Abdulwahab \& Zulkhairi, 2012). Also registration at the cafes often is cheaper, faster and more convenient to have the café operators to get into the myBUK portal and implements the registration process for them. Such students who do not use the portal themselves are not likely to say that the system is easy to use. Regarding social influence, the results are similar to performance expectancy in the sense that the respondents are not likely to feel that their friends, relatives or important others would feel the need for them to use the system. It is simply a necessary process that must be completed at the beginning of each academic session. On the other hand, many of the respondents would agree that there is substantial organizational and technical infrastructure that exists to support use of the myBUK registration portal. Anyone who uses the portal or sees it being used is likely to get that impression considering how the entire registration and payment processes are now done through the portal. Students that knew the difficulties of the earlier manual system are especially likely to agree with this construct. In the same way, many of the respondents would agree with the anxiety construct because of the stress associated with the consequences of not using the portal during the registration period.
The implication of our finding in the context of this research suggests that the general UTAUT model, popular as it has become in explaining user acceptance of many IT based systems, is not universally applicable to all IT systems. We have seen that three of the main constructs of the UTAUT model, performance expectancy, effort expectancy and social conditions, have not been satisfied for a university registration portal. This means that the acceptance and use model of systems such as the university registration portal in this study is markedly different from the other IT platforms where original UTAUT model thrive.

\section{Conclusions}

This study tried to validate a modified UTAUT model for the "myBUK" portal, a university registration system used by undergraduate students. The study found that three major constructs of the model performance expectancy (PE), effort expectancy (EE) and social influence (SI) - are not satisfied while the remaining two constructs - facilitating conditions (FC) and anxiety $(A X)$ - are confirmed. The research shows that, in spite of the popularity of UTAUT, there are a number of IT platform that may neither fit into the UTAUT nor UTAUT2 models because of their special characteristics. There is the need to further investigate into such systems in order to identify them and formulate appropriate use and acceptance models for them.

Conflict of Interest: The authors have declared that no conflicting interests exist in their work.

Contribution of Authors: This work was carried out in collaboration between the two authors'; they have both read and approved the final manuscript.

Acknowledgements: The authors acknowledged the support from our research assistants and the entire respondents who participated in the research. We thank the anonymous reviewers for sparing their valuable time in reviewing our work. 


\section{REFERENCES}

Abdulwahab, L., \& Zulkhairi, M.D. (2012). Modeling the determinants and gender, age and ethnicity differences in telecommunication centre acceptance. Research Journal of Information Technology, 4(3), 85-105.

Ajzen, I. (1991). Theory of planned behavior. Organizational Behavior and Human Decision Processes, 179-211.

Anderson, J., \& Gerbing, D. (1988). Structural equation modeling in practice: A review and recommended two-step approach. Psychological Bulletin, 103(3), 411-423.

Bagozzi, R., \& YI, Y. (1988). On the evaluation of structural equation mode. Journal of Academy of Marketing Science. , 16 (1), 7494.

Bandura, A. (1986). Social foundations of thought and action: $A$ social cognitive theory. NJ : Prentice Hall, Englewood Cliff.

Bhattacherjee, A. (2001). Understanding use continuance: An expectation-confirmation model. MIS Quarterly, 25(3), 351-370.

Browne, M., \& Cudeck, R. (1993). Alternative ways of assessing model fit,. Sage Publications, Newbury Park.

Byrne, M. (2010). Structural Equation Modeling With AMOS: Basic Concepts, Applications, and Programming, 2nd edition,. 270 Madison Avenue New York, NY 10016: Routledge Taylor \& Francis Group

Chau, P., \& HU, P. (2001). Information technology acceptance by individual professional: A model comparison approach. Decision Sciences, 32 (4), 699-719.

Chin, W. (2010). How to write up and report PLS analyses. Handbook of partial least squares: Concepts, methods and application. New York:: Springer.

Campeau, D. R., and Higgins, C. A. "Application of Social Cognitive Theory to Training for Computter Skills," Information Systems Research (6:2), 1995, pp. 118-143.

Davis, F. (1989). Perceived usefulness, perceived ease of use and user acceptance of information technology. MIS Quarterly, 13(3), 319-340.

Davis, F., Bagozzi, R.P, \& Warshaw,P.R. (1989). User Acceptance of Computer Technology: A Comparison of Two Theoretical Models. Management Science 35(8) , pp. 982- 1003.

Davis, F. D., Bagozzi, R. P., and Warshaw, P. R. "Extrinsic and Intrinsic Motivation to Use Com-puters in the Workplace," Journal of Applied Social Psychology (22:14), 1992, pp. $1111-1132$

Fishbein, M., \& Ajzen, I. ( 1975). Belief, attitude, intention and behavior: An Introduction to theory and research. Reading,. MA: AddisonWesley.
Fornell, C., \& Larcker, D. (1981). Evaluating structural equation models with unobservable variables and measurement error. Journal of Marketing Research , 18 (1), 39-50.

Gefen, D., \& Straub, D. W. (2005). A practical guide to factorial validity using PLS-graph: Tutorial and annotated example. Communications of the AIS , 16(5), 91-109.

Hair, J., Black, W., Babin, B., Andersen, R., \& Tatthham, R. (2010). Multivariate data analysis (7th ed.). NJ: Upper Saddle River, Pearson Prentice Hall.

Karahanna, E., Straub, D.W , \& Chervany, N. (1999). Information Technology Adoption across Time: A Cross-Sectional Comparison of PreAdoption and Post-Adoption Beliefs. MIS Quarterly, 23(2), 183-213.

Liao, J., Tsou, C , \& Shu, Y. (2008). The Roles of Perceived Enjoyment and Price Perception in Determining Acceptance of Multimedia-onDemand. International Journal of Business and Information. 3(1), 27-52.

Nunnally, J., \& Bernstein, I. (1994). Psychometric theory (3rd ed.). New-York: McGraw-Hill.

Rogers, E. Diffusion of Innovations, Free Press, New York, 1995.

Sekaran, U. (2006). Research methods for business: $A$ skill building approach. New York: John Wiley \& Sons, Inc.

Taylor, S., and Todd, P. A. "Assessing IT Usage: The Role of Prior Experience," MIS Quarterly (19:2), 1995, pp. 561-570.

Thompson, R. L., Higgins, C. A., and Howell, J. M. "Personal Computing: Toward a Conceptual Model of Utilization," MIS Quarterly (15:1), 1991, pp. 124-143.

Venkatesh, V., \& Davis, F. (2000). A theoritical extension of the technology acceptance model: For longitudinal fieild studies. Management Science, 46(2), 186-204.

Venkatesh, V., Morris, M, Davis, G, \& Davis, F. (2003). User acceptance of information technology: toward a unified view. MIS Quarterly, 27(4), 425-478.

Venkatesh, V. Z., \& Sykes S. (2011). Just what the Doctor ordered: A revised UTAUT for EMR system adoption and use by Doctors. 44th Hawaii International conference on system sciences, (pp. 1-10). Hawaii: hicss.

Venkatesh, V., Thong, J.Y.L, \& Xu, X. (2012). Consumer Acceptance and Use of Information Technology: Extending the unified theory of acceptance and use of technology,. MIS Quarterly 36 (1), 156- 178. 